\title{
Early reporting of myocardial infarction: impact of an experiment in patient education
}

\author{
J M ROWLEY, J D HILL, J R HAMPTON, J R A MITCHELL
}

\begin{abstract}
Many deaths from myocardial infarction occur before medical help is sought. A campaign was mounted in Nottingham ("Nottingham Heartwatch") to encourage early reporting. A total of 13828 men and women aged 40 and over registered with three general practices were asked to telephone a hospital-based number if they developed chest pain lasting for more than 10 minutes. Patients from study practices reported chest pain earlier after our invitation than they had before and also earlier than patients from control practices. While accepting the advice to call early some patients from the study practices ignored our special number and telephoned their general practitioner. The calls received on the Heartwatch line yielded a lower percentage of definite and probable infarcts than the calls received by the patients' own doctors.

The way in which the characteristics of the study practices might have influenced this difference is discussed since it has considerable implications for largerscale attempts to bring patients with suspected myocardial infarction under medical care at the earliest opportunity.
\end{abstract}

\section{Introduction}

Myocardial infarction claims almost 110000 lives in England and Wales each year ${ }^{1}$ and many of the deaths occur before medical help is sought or can be made available. Attempts have therefore been made to accelerate the provision of aid to the victim of a heart attack once a call for help has been made (mobile coronary

\footnotetext{
Department of Medicine, University Hospital, Queen's Medical Centre, Nottingham NG7 2UH

J M ROWLEY, MA, MRCP, lecturer in medicine

J D HILL, DM, MRCP, lecturer in medicine (now: senior registrar in medicine, St Luke's Hospital, Bradford)

J R HAMPTON, DM, FRCP, professor of cardiology

J R A MITCHELL, MD, FRCP, professor of medicine
}

care $^{2-4}$; paramedical flying squads ${ }^{56}$; and training the general public in resuscitation ${ }^{7}{ }^{8}$ ) but less attention has been given to accelerating the initial call for help. Half the deaths from an episode of myocardial infarction occur within two hours of the onset of symptoms ${ }^{9-12}$ but many studies have shown that patients are reluctant to seek help in these first critical hours. ${ }^{9-14}$ We found that in the practices taking part in our earlier comparison of home versus hospital management of suspected infarction ${ }^{15}$ only $40 \%$ of the patients called for help within an hour of onset and by the end of two hours the total was $60 \%$; some $40 \%$ of the patients with infarcts had therefore not sought help by this time.

Though some of the early deaths from coronary disease are "sudden" or "instantaneous" and therefore not amenable to management by conventional medical services, many patients could benefit from earlier help if they drew attention to themselves in the earliest stages of their illness. As there has been no major attempt to establish whether any form of health education influences the behaviour of individuals suffering from chest pain by persuading them to call for help at an early stage, we decided to mount an early reporting campaign ("Nottingham Heartwatch") in such a way that its effects could be monitored.

We contacted patients aged 40 and over who were registered with three of the general practices that had participated in our earlier study. ${ }^{15}$ The value of early attention to patients with chest pain was outlined and the recipients were asked to ring a special telephone number if they had chest pain for more than 10 minutes. The pattern of calls received from the study population could then be compared with the pattern in the study practices before the campaign, and with calls before and during the campaign in the remaining practices whose patients had not been contacted. We report the results of our study.

\section{Methods}

We selected three group practices from the 13 practices that had participated in our study of home versus hospital care for myocardial infarction. ${ }^{15}$ These three were chosen because of their location (two were situated in suburban Nottingham and one in an independent small town on the edge of metropolitan Nottingham) and because they had age/sex registers that enabled us to identify all the individuals aged 40 or above in these practices. A total of 13828 individuals were then invited to make use of a system designed to provide early help in the 
diagnosis and management of symptoms suggestive of myocardial infarction. A letter outlining the value of early help in suspected heart attack drew attention to the possible importance of chest pain lasting for longer than 10 minutes and focused attention on this by means of a logo or campaign symbol: it described the availability of a hospitalbased team to visit any patient with persistent chest pain and invited the patient to contact this team on an easy-to-remember number, which served a direct telephone line to the hospital coronary care unit. With the letter the patient received self-adhesive stickers to apply to the telephone or first-aid cabinet and a card to carry in the handbag or wallet: the telephone number was prominent in all these. The blue envelope and enclosed information was designed to avoid alarm and to provide a positive approach, since health campaigns based on fear are thought to be counterproductive. We designed the envelope and its contents in conjunction with a creative design studio.

The incoming calls were received by members of the nursing staff of the coronary care unit (the despatchers), who had been provided with a message pad bearing a written protocol requiring them to establish where the caller was, whether the patient was suffering chest pain or other symptoms, and whether the patient was registered with one of our study practices.

If the patient was registered with one of our three study practices the mobile hospital-based team was sent to any patient at home who had had chest pain for more than 10 minutes and less than 24 hours, or who had had any other symptoms suggestive of myocardial infarction. The team consisted of a state registered nurse from the coronary care unit and a senior house officer, who could be contacted by emergency bleep and asked to give advice to the caller if the despatcher was uncertain about the action required. The team then drove to the patient's home in an estate car equipped with a portable electrocardiograph, defibrillator, equipment for intubation and ventilation, and appropriate cardiac drugs. If the patient was registered with a study practice but the symptoms were not suggestive of myocardial infarction the despatcher arranged for the patient's general practitioner to visit as soon as possible. If the symptoms did suggest infarction but the despatch of the team was impossible-for example, if they were attending another call or the car or equipment were under repairor inappropriate-for example, if the patient was not at home-then the despatcher sent an emergency ambulance to the scene with instructions to bring the patient to the casualty department of our hospital.

If the call was from a patient who was not registered with our three participating practices the despatcher was asked to arrange for the general practitioner to attend unless she felt that the clinical description given by the caller suggested that immediate action was necessary, in which case she was empowered to send either our team or an emergency ambulance.

When the team arrived in the patient's home they made a clinical assessment, recorded an electrocardiogram, and provided any necessary treatment. If, at the end of two hours, the patient was socially and medically fit for home care according to previously published criteria, ${ }^{15}$ the team left the patient at home under the supervision of the general practitioner. Otherwise, the patient was admitted to hospital under the care of the trial team. In either case serial electrocardiograms were studied and cardiac enzyme activities measured for two days to classify the patients.

Definite myocardial infarction was diagnosed on a convincing history plus changes in the electrocardiogram diagnostic of recent infarction and raised activities of serum aspartate aminotransferase and serum hydroxybutyrate dehydrogenase to more than twice the upper limit of normal.

Probable myocardial infarction was diagnosed with a convincing history plus either changes in the electrocardiogram highly suggestive of recent infarction or changes in the electrocardiogram not typical of recent infarction but associated with activities of serum aspartate aminotransferase and serum hydroxybutyrate dehydrogenase raised to more than twice the upper limit of normal.

Possible myocardial infarction was considered in cases of a convincing history plus either abnormalities in the electrocardiogram not typical of recent infarction or serum aspartate aminotransferase or serum hydroxybutyrate dehydrogenase activities above the upper limit of normal.

Ischaemic heart disease was diagnosed in patients with a convincing history plus electrocardiographic evidence of old infarction.

Chest Pain ? cause was diagnosed with a convincing history in a patient with normal appearances on serial electrocardiograms and normal activities of serum aspartate aminotransferase and serum hydroxybutyrate dehydrogenase.

All calls from patients registered with our study practices were followed up after six weeks to establish survival: patients seen by the team were seen in a hospital clinic and patients whose own doctor had attended were traced through the doctor concerned.

During the study the team was also available to all the 60 general practitioners who had previously taken part in the home versus hospital study, irrespective of whether their patients had been supplied with the Heartwatch information. The team was willing to attend the home of any patient whom the general practitioner suspected of having a myocardial infarct. We were thus able to compare not only the pattern of calls on the Heartwatch line with the pattern of calls received from the three study practices before the Heartwatch information had been sent (before and after periods in study practices) but also the pattern of calls received by the team from control practices before and after the information was sent to the study practices (before and after in control practices). This allowed us to determine the direct effect of our mailing as opposed to any general secular shift in patterns of patient behaviour that might have occurred in response to other forms of patient education at international, national, and local level-for example, the death or rescue from coronary disease of a famous person could have drawn attention to the need for early contact with the medical services. Particular attention was paid to the interval from the onset of the symptoms responsible for the call to the call itself.

Finally, we also monitored all admissions for suspected infarction to the two Nottingham hospitals during the study period, thereby identifying patients from the study and control practices who had bypassed the direct Heartwatch line, or whose general practitioners had bypassed the team, and enabling us to document the referral patterns from the patients of the remaining 204 general practitioners who had not taken part in either Heartwatch or the original home versus hospital project. The results from this wider comparison will form part of another report on the effect of education about coronary disease on general practitioner's behaviour, whereas the present report deals with its impact on patients' behaviour.

In June 1978, a year after the original contact, a second letter was sent to 13250 of the original group (578 were deleted from the original mailing list because of inaccuracies in the age/sex register). This second contact was designed to remind individuals of the existence of the service and provided a duplicate of the telephone number cards sent with the original letter. In January 1980, 12452 individuals were informed of the withdrawal of the Heartwatch service.

\section{Results}

From March 1977 to January 1980 we received 242 calls.
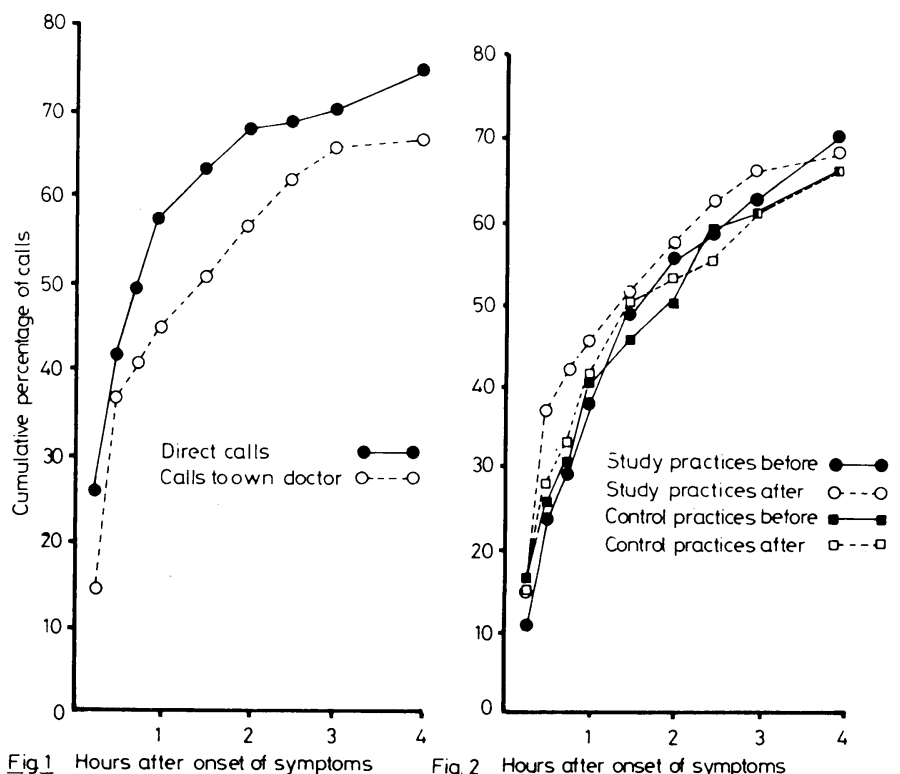

FIG 1-Cumulative percentage of calls received at various intervals after onset of symptoms from patients in study practices who used the direct line $(n=101)$ or who called their general practitioner $(n=86)$. FIG 2-Cumulative percentage of calls received by general practitioners at various intervals after the onset of symptoms, comparing those received from study practices before $(n=191)$ and after $(n=86)$ Heartwatch and from control practices before $(n=231)$ and after $(n=139)$ Heartwatch. 


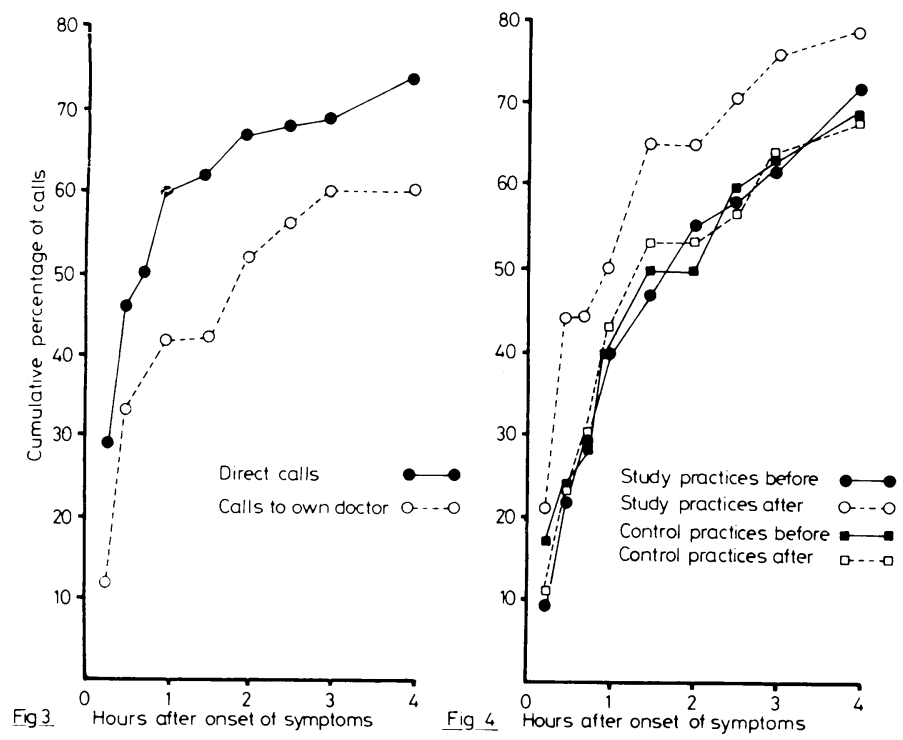

FIG 3-Cumulative percentage of calls received on direct line $(n=84)$ or by general practitioners $(n=52)$ at various intervals after onset of symptoms from patients in study practices who were not thought to have myocardial infarction. FIG 4-Cumulative percentage of calls received by general practitioners at various intervals after onset of symptoms from patients who had definite or probable myocardial infarction. Calls from study practices before Heartwatch $(n=92)$ are compared with those after $(n=34)$ and with those from control practices before $(n=103)$ and after $(n=53)$ Heartwatch.
Fig 3 shows the calls received after our letter for patients in the study practices in whom definite or probable infarction was not diagnosed. It compares those using our direct number with those who had contacted their general practitioner and shows a major acceleration of times of call in the former $(60 \%$ had called us by one hour compared with $42 \%$ who called their own doctor; $p<0.05$ ). A similar analysis of the patients in whom definite or probable infarction was the final diagnosis did not, however, show a significant difference between the time of calls to our direct line and to their general practitioner. Figure 4 shows that the patients with definite and probable infarction were calling their own general practitioners significantly earlier as a result of Heartwatch, whereas the patients with definite and probable infarcts from the control practices had not changed their behaviour during our study (percentage calling by 30 minutes-study practices before $22 \%$ and during $-44 \%, \mathrm{p}<0.05$; control practices before $24 \%$ and during $23 \%$ ).

A random sample of the callers on our direct line were asked whether they had tried to contact their own doctor before dialling Heartwatch and of the 69 sampled, $22(32 \%)$ indicated that they had.

\section{ACTION TAKEN BY DESPATCHERS}

Nine callers ( $4 \%$ of total) did not provide adequate information to allow the despatcher to take action. Fifty calls $(21 \%$ of total) came from patients who had not been sent the Heartwatch invitation (fig 5) but who had learnt of our direct telephone number and the exhortation to use it in many different ways (through their spouses where husbands and wives were registered with different doctors; through a neighbour, or through first-aid rooms in factories that had been supplied with our number by an employee). The general practitioner was despatched to

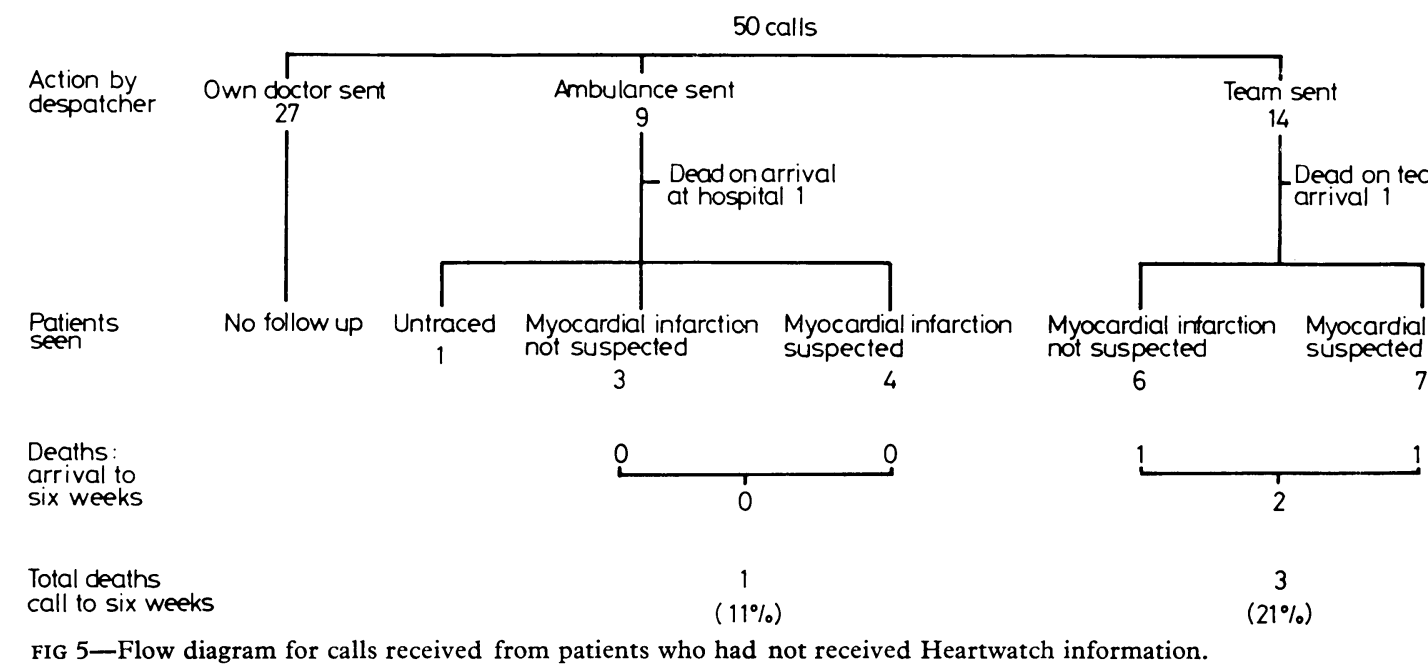

\section{EFFECT OF HEARTWATCH ON TIME OF CALL}

The figures show the cumulative percentage of the first calls for help from the patients to our direct line or to their own general practitioner at various intervals after the onset of symptoms. Fig 1 shows that at all intervals up to four hours after onset of symptoms, a greater percentage of calls from patients in the study practices had been received by the Heartwatch line than by the general practitioners (58\% direct calls at one hour from onset as opposed to $45 \%$ to the general practitioner). Fig 2 shows the pattern of calls for suspected infarction to the general practitioners in the study practices before and after their patients had received information on Heartwatch and compares it with the pattern of calls during these two periods to those general practitioners whose patients had not received the Heartwatch invitation. Study practices before the invitation and control practices before and during the study show a remarkably similar pattern of calls. Patients in the study practices, however, called their general practitioner earlier after receiving Heartwatch information $(37 \%$ had called by 30 minutes from onset of symptoms compared with $24 \%$ before Heartwatch; $p<0.05)$. Some recipients of our letter thus complied with one of its suggestions (to call early if they had chest pain) but rejected our invitation to use our direct telephone number, choosing instead to seek help from their own doctor.
27 of these contacts and we had no mandate to follow them up any further. Of the remaining 23 calls, two patients were dead on arrival at hospital by ambulance or when the team arrived at the home (both had thrombotic coronary occlusions at necropsy). Of the survivors, 11 were suspected of having myocardial infarction on arrival in hospital by ambulance or on the arrival of our team at their home and two patients seen and admitted by the team died within six weeks (one patient with a probable anterior infarct died of severe heart failure 24 hours after admission and one patient with heart failure developed evidence of definite infarction and died 12 days after admission of heart failure, pneumonia, and pulmonary emboli). There were thus four deaths from the 23 calls ( $17 \%$ mortality) received from nonparticipating patients in whom the despatcher judged that the clinical situation warranted the use of an ambulance or our team.

Most of the calls ( $76 \%$ ) came from registered participants (fig 6 ) and the despatcher judged that the general practitioner should be asked to visit 56 because the telephone contact did not suggest that myocardial infarction had occurred. One of these patients was dead when the doctor arrived (known inoperable bladder carcinoma) and of the remaining 55, $48(87 \%)$ were not suspected of having myocardial infarction by the attending doctor. Only one patient in this subgroup died (known inoperable stomach carcinoma). Infarction was suspected by the attending doctor in seven patients, one of whom died the same 
day at home, the cardiac enzyme activities and appearances in the electrocardiogram having been normal at that stage. The overall mortality in the group visited by their own doctor was thus $3 / 56(5 \%)$ and contrasts sharply with the 15 deaths $(12 \%)$ occurring in the remaining 127 participating patients to whom an ambulance or the team was sent. The despatcher had therefore been able to differentiate between high and low risk situations.

An ambulance was sent to 23 participating callers; one was dead when the vehicle arrived but was brought to hospital to be formally certified. One death occurred in the nine patients not suspected of infarction (metastatic bronchial carcinoma) and one in the 13 patients suspected of infarction (resuscitated from asystole in the casualty department but died after three days in the intensive care unit) giving a total mortality at six weeks of $3 / 23(13 \cdot 0 \%)$. our request to ring our special number; secondly, 91 patients in the participating practices who ignored our request and rang their general practitioner and, finally, 146 patients from the control practices to whom our team was available, but whose patients had received no information and whose behaviour should have been unaffected by Heartwatch. There are no major differences in age and sex structure, but as one would expect a higher percentage of the patients whose initial calls had already been filtered by the general practitioner were suspected of having myocardial infarction by the team. Table II shows that this difference was carried through into the strength of the final diagnosis $(45 \%$ of the patients who called their own doctor and $33 \%$ of those to whom the team was sent direct were diagnosed as having definite and probable infarcts). Nevertheless, the total mortality six weeks after the calls and the mortality in those

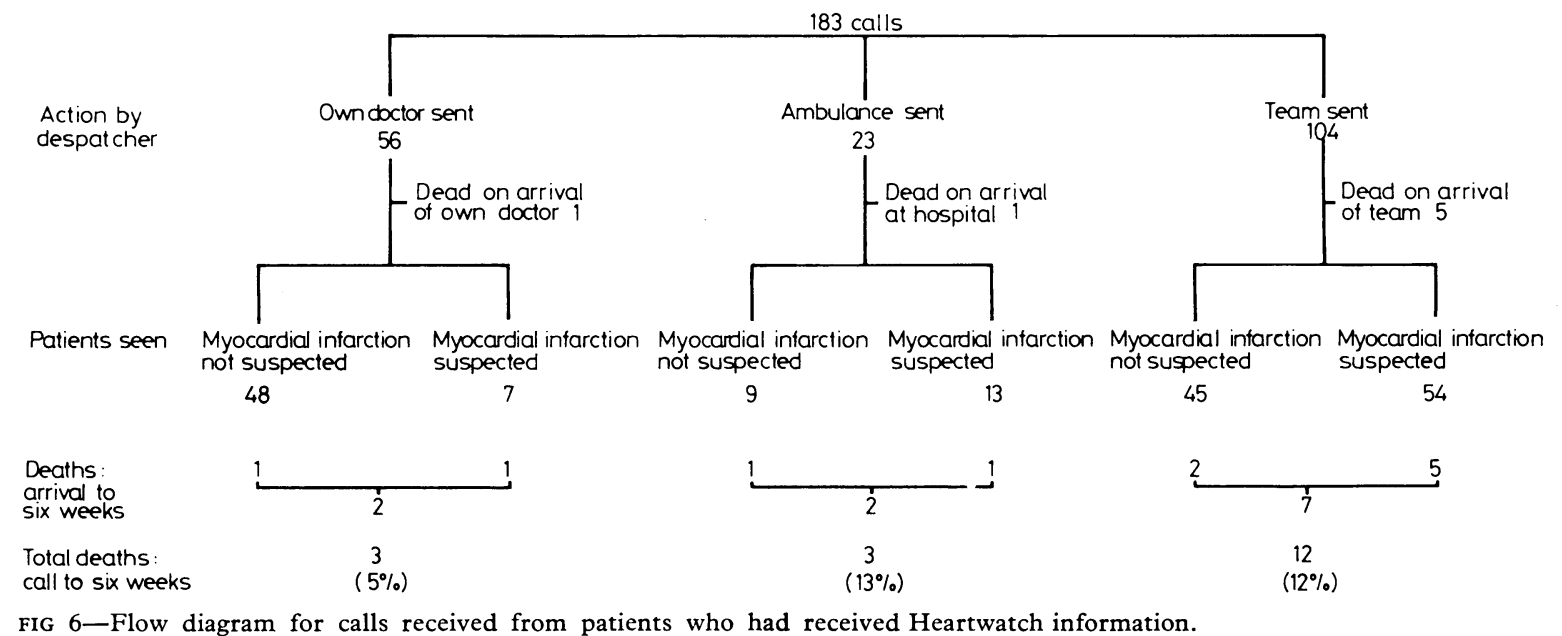

The team visited 104 patients and found five of them to be already dead (in four sudden death had precipitated the call for help while the fifth patient had already been discharged from hospital after a definite myocardial infarction, and had suddenly developed symptoms of left ventricular failure). Of the survivors, 45 were judged not to have myocardial infarction; two died within six weeks (the first of bronchial carcinoma at home, the second of left ventricular failure and bronchopneumonia in hospital). Myocardial infarction was suspected in 54, and by the sixth week, five had died. Two of these patients had definite infarcts; one died from heart failure after five weeks in hospital while the other died suddenly at home after two weeks: the remaining three patients had probable infarcts; two died suddenly at home, two and three weeks after the onset, and one in hospital after two weeks, of pulmonary emboli.

\section{IMPACT OF HEARTWATCH ON WORK LOAD}

Our campaign could have engendered anxiety and generated a flood of unnecessary calls that would have overwhelmed a general practitioner had his been the telephone number offered. In the event, the service was not overloaded nor were the calls considered to be unnecessary. A further possibility was that our callers would not previously have called for help, however real their need, so that they would have represented an additional load to those previously contacting their practitioners. Before Heartwatch, the participating general practitioners were calling out our team to visit patients with suspected infarcts on an average of 4.6 occasions per month; this fell to $2 \cdot 6$ per month after Heartwatch. Some of the $5 \cdot 4$ calls received by Heartwatch from these practices each month thus represented a rerouting of the call for help in accordance with our request in the mailing, whereas the remainder were clearly additional calls not previously reaching us.

\section{CHARACTERISTICS OF PATIENTS VISITED BY THE TEAM}

Table I shows the three groups of patients visited by our team. Firstly, the 104 patients in participating practices who complied with

initially suspected of infarction $(9 \%$ in Heartwatch calls; $11 \%$ in calls to general practitioners from the participating practices; $10 \%$ in calls to general practitioners from control practices) did not differ significantly. All deaths in the self-referred group occurred in patients with definite or probable infarcts; in the calls to general practitioners from the study practices, seven of the eight deaths occurred in patients with definite or probable infarcts, while in control practices, seven of the 12 deaths occurred in patients with definite or probable infarction.

TABLE I-Characteristics of callers to whom our team was sent (percentages for each group of callers in parentheses)

\begin{tabular}{lcccc}
\hline & \multicolumn{2}{c}{ Study practices } & & Control practices \\
\cline { 2 - 3 } \cline { 5 - 5 } & $\begin{array}{c}\text { Call to } \\
\text { Heartwatch } \\
(\mathrm{n}=104)\end{array}$ & $\begin{array}{c}\text { Call to } \\
\text { own doctor } \\
(\mathrm{n}=91)\end{array}$ & & $\begin{array}{c}\text { Call to } \\
\text { own doctor } \\
(\mathrm{n}=146)\end{array}$ \\
\hline No of men: & $76(73)$ & $56(62)$ & & $107(73)$ \\
Mean age (years) & 61 & 60 & 56 \\
No of women: & $28(27)$ & $25(38)$ & & $39(27)$ \\
Mean age (years) & 62 & 67 & & 59 \\
No with suspected infarcts & $54(52)$ & $75(82)$ & & $124(85)$ \\
No of deaths by six weeks & $12(12)$ & $10(11)$ & & $14(10)$ \\
\hline
\end{tabular}

TABLE II-Final diagnosis and outcome in callers classified by visiting team as having suspected myocardial infarction (percentages for each group of callers in parentheses)

\begin{tabular}{|c|c|c|c|}
\hline & \multicolumn{2}{|c|}{ Study practices } & \multirow{2}{*}{ 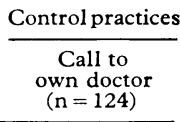 } \\
\hline & $\begin{array}{l}\text { Call to } \\
\text { Heartwatch line } \\
(\mathrm{n}=54)\end{array}$ & $\begin{array}{l}\text { Call to } \\
\text { own doctor } \\
(\mathrm{n}=75)\end{array}$ & \\
\hline \multicolumn{4}{|l|}{$\begin{array}{l}\text { Diagnosis: } \\
\text { Definite/probable }\end{array}$} \\
\hline myocardial infarction & $18(33)$ & $34(45)$ & $55(44)$ \\
\hline Possible myocardial infarction & $19(35)$ & $22(29)$ & $41(33)$ \\
\hline $\begin{array}{l}\text { Ischaemic heart disease } \\
\text { Chest pain ?cause }\end{array}$ & $\begin{array}{c}3(6) \\
14(26)\end{array}$ & $17(23)$ & $\begin{aligned} 2(2) \\
24(19)\end{aligned}$ \\
\hline $\begin{array}{l}\text { Chest pain ?cause } \\
\text { Not myocardial infarction }\end{array}$ & $14(26)$ & $\begin{array}{l}17(23) \\
2(3)\end{array}$ & $\begin{array}{c}24(19) \\
2(2)\end{array}$ \\
\hline Deaths by six weeks & $5(9)$ & $8(11)$ & $12(10)$ \\
\hline
\end{tabular}




\section{Discussion}

Our results show that the time between the onset of chest pain and the first call for help was shortened by sending a letter to men and women aged 40 and over in three general practices in Nottingham. We need to put our findings into perspective before we consider the implications for health-education strategy in general or attempt to compare our study with the small number of similar studies reported.

Firstly, the practices taking part in Heartwatch were selected from the 13 who had already taken part in our previous study. ${ }^{15}$ These practices differed appreciably from many of the remaining general practices in our city, particularly in that none of them used external deputising services. Thus their patients with chest pain faced with our request to ring an unknown individual, albeit in a known institution, on our special line knew that if they rang their general practice they would either reach their own doctor or his internal and known deputy. This is crucially important to the finding that our letter had shortened the time from onset of symptoms to the call for both general practitioners and our direct line. Some callers had thus complied with our request to ring early but had chosen to ignore the special number, preferring instead to contact their own general practitioners. If the study patients had been drawn from practices using a commercial deputising service would the early callers have chosen the known institution (our hospital) and its anonymous doctors in preference to the deputising switchboard with its anonymous doctors? Our later report on the impact of our studies in coronary care on the remaining general practices in Nottingham will attempt to answer this question.

To allow us to measure the effect of our scheme we used direct mailing rather than the mass media, so that we could compare study and control practices. Nevertheless, a fifth of our calls came from individuals who had not received Heartwatch information. We asked our local media (two radio stations and a newspaper) not to draw attention to the scheme but despite this, our message spread laterally into the community (within families, across garden walls, and within factories and clubs). This suggests that public awareness could be readily assured in a more general campaign backed by the use of the local media. Our results also show that our nurse-despatchers were able to extract enough information from the telephone calls to differentiate between patients who would and who would not be suspected of having myocardial infarction when seen by a doctor and between high and low risk groups.

Finally, and of great interest, is the difference that occurred between our wholly compliant patients (rang early and rang us) and the partially compliant patients (rang early but rang their own doctor) in that the chosen route correlated with their eventual diagnosis. The patients with the highest chance of being classified as having definite or probable myocardial infarction were more likely to ring their own doctor, while patients with a lower rate of definite or probable myocardial infarction rang us. What characteristics at the onset of these illnesses could have prompted this, since several days had to elapse before the findings in electrocardiogram and enzyme studies would allow us to make this differentiation? It seems likely to relate to the severity of symptoms such as pain, in that within our chosen practices, the patients who knew that they were ill and needed rapid relief would turn to their doctor whereas the patients who thought that they were not ill and wanted reassurance would be less reluctant to call out our team than to "bother the doctor unnecessarily."

In attempting to reduce delay by patients, we need to understand its causes. Many studies have examined the variables associated with delay in seeking help for symptoms of myocardial infarction. The effect of age is by no means clear. Theorell et $a l^{16}$ showed a shorter delay in admission to hospital in patients aged less than 65 and Moss et al ${ }^{17}$ showed a progressive increase in decision time with age. Tjoe et a ${ }^{18}$ however, were unable to show such an effect. Hackett and Cassem $^{19}$ showed a reduction in delay when symptoms were recognised as cardiac, but this difference was not shown by Erhardt et al. ${ }^{20}$ Tunstall Pedoe et $a l^{21}$ in their study of heart attacks in East London found that even in patients with known coronary heart disease, only $37 \%$ suspected that another myocardial infarction may have occurred when they developed new symptoms, $23 \%$ were unable to hazard a guess as to its cause, and $8 \%$ thought that they had indigestion. One might expect that previous experience of manifestations of coronary heart disease would reduce patient delay in subsequent episodes, but many studies show no effect 19202223 and indeed Gudmundsson et $a l^{24}$ showed a longer delay in patients during a second attack. Though intensive education programmes have been developed in America ${ }^{25}$ and Finland ${ }^{26}$ to try to reduce the risk factors for ischaemic heart disease by encouraging the population to change their lifestyle, there have been few attempts to alter the behaviour of individuals once symptoms have developed. McNeill et al reported the results of a public education programme in Dundee, conducted through the local press, and television and offering direct access to a mobile coronary care unit. ${ }^{27}$ The median call time for the patients using this facility was 60 minutes but no data were presented to indicate whether there had been any change as a result of the campaign. Moreover, despite the use of the mass media to draw attention to the service, only eight calls were received each month from their catchment population of 200000 compared with 5.6 per month from our 13828 patients contacted. Because our study was limited to three of the practices for which we had detailed information on the pattern of calls before our campaign, we were able to compare patient behaviour before and during our study in the study and control practices.

We were consistently impressed by the responsible use which had been made of our invitation, the high level of awareness among the study patients of the availability of the service, and the use made of the leaflets and the telephone stickers, which were prominently displayed in the homes visited. We therefore believe that patient behaviour may be appreciably altered in the acute phase of suspected myocardial infarction and this study encourages us to develop similar educational activities in our population on a larger scale so that an effect on outcome and not just on call times and diagnostic patterns may be determined.

We are grateful to the general practitioners in the Arnold and Long Eaton Health Centres for their encouragement and help with Heartwatch and to all the practices taking part in this and in our othe studies, to the coronary care nurses who dealt so capably with the incoming calls, and to our senior house officers who formed the homevisit team.

The study was made possible by grants from the Department of Health and Social Security and the Health Education Council and the specially equipped estate car was provided and maintained by the Beechdale depot of the Nottinghamshire Area Health Authority Ambulance Service. The Heartwatch logo and mailing was developed in conjunction with $\mathrm{Mr}$ Michael Brayley and the staff of the Players Creative Design Studio. The mailing to patients was carried out in conjunction with Mrs Pam Norris of Midland Direct Advertising.

Reprint requests to Professor J R A Mitchell.

\section{References}

1 Office of Population Censuses and Surveys. Mortality statistics 1979 England and Wales. London: HMSO, 1981.

2 Pantridge JF, Geddes JS. A mobile intensive-care unit in the management of myocardial infarction. Lancet $1967 ; \mathrm{ii} \cdot 271-3$.

${ }^{3}$ Hampton JR, Nicholas C. Randomised trial of a mobile coronary care unit for emergency calls. Br Med f 1978;i:1118-21.

${ }^{4}$ Briggs RS, Brown PM, Crabb ME, et al. The Brighton resuscitation ambulances: a continuing experiment in pre-hospital care by ambulance staff. $B r$ Med $\mathcal{F} 1976$;ii:1161-8.

${ }^{5}$ Cobb LA, Alvarez H, Copass MK. A rapid response system for out-ofhospital cardiac emergencies. Med Clin North Am 1976;60:283-90.

${ }^{6}$ Eisenberg MS, Bergner L, Hallstrom A. Out-of-hospital cardiac arrest: improved survival with paramedic services. Lancet $1980 ; \mathrm{i}: 812-5$.

7 Thompson RG, Hallstrom AP, Cobb LA. Bystander-initiated cardiopulmonary resuscitation in the management of ventricular fibrillation. Ann Intern Med 1979;90:737-40. 
${ }^{8}$ Copley DP, Mantle JA, Rogers WJ, Russell RO Jr, Rackely CE. Improved outcome for prehospital cardiopulmonary collapse with resuscitation by bystanders. Circulation $1977 ; \mathbf{5 6}: 901-5$.

${ }^{9}$ Armstrong A, Duncan B, Oliver MF, et al. Natural history of acute coronary heart attack. A community study. Br Heart $\mathcal{f} 1972$;34:67-80

${ }^{10}$ Bainton CR, Peterson DR. Deaths from coronary heart disease in persons fifty years of age and younger. A community-wide study. $N \mathrm{Englf}$ Med $1963 ; 268: 569-75$.

${ }^{11}$ Kinlen LJ. Incidence and presentation of myocardial infarction in an English community. Br Heart $\mathcal{f} 1973 ; 35: 616-22$.

12 McNeilly RH, Pemberton J. Duration of last attack in 998 fatal cases of coronary artery disease and its relation to possible cardiac resuscitation. Br Med f 1968;iii:139-42.

${ }^{13}$ Smyllie HC, Taylor MP, Cuninghame-Green RA. Acute myocardial infarction in Doncaster. II-Delays in admission and survival. $\mathrm{Br}$ Med $\mathcal{F}$ $1972 ; \mathrm{i}: 34-6$.

14 Colling A, Dellipiani AW, Donaldson RJ, MacCormack P. Teesside coronary survey: an epidemiological study of acute attacks of myocardial infarction. Br Med F 1976;ii:1169-72.

${ }^{15}$ Hill JD, Hampton JR, Mitchell JRA. A randomised trial of home-versushospital management for patients with suspected myocardial infarction. Lancet $1978 ; \mathrm{i}: 837-41$.

16 Theorell T, Erhardt LR, Lind E, Sjögren A, Säwe U. Selected psychosocial variables in the delay of reaching the coronary care unit. Acta Med Scand 1975;198:315-7.

17 Moss AJ, Wynar B, Goldstein S. Delay in hospitalization during the acute coronary period. Am $\mathcal{F}$ Cardiol 1969;24:659-65.
18 Tjoe SL, Luran MH. Delays in reaching the cardiac care unit. An analysis. Chest $1972 ; 61: 617-21$.

19 Hackett TP, Cassem NH. Factors contributing to delay in responding to the signs and symptoms of acute myocardial infarction. Am $\mathcal{f}$ Cardiol $1969 ; 24: 651-8$.

${ }^{20}$ Erhardt LR, Sjögren A, Säwe U, Theorell T. Prehospital phase of patients admitted to a coronary care unit. Acta Med Scand 1974;196:41-6.

21 Tunstall Pedoe H, Clayton D, Morris JN, Brigden W, McDonald L. Coronary heart attacks in East London. Lancet 1975; ii :833-8.

22 Schroeder VS, Lamb IH, Hu M. The prehospital course of patients with chest pain. Analysis of the prodromal, symptomatic, decision-making, transportation and emergency room periods. Am 7 Med 1978;64:742-8.

${ }^{23}$ Simon AB, Feinleib M, Thompson HK Jr. Components of delay in the pre-hospital phase of acute myocardial infarction. Am $\mathcal{F}$ Cardiol 1972; $30: 476-82$.

24 Gudmundsson S, Hardarson T. The determination of the duration of admission delay in acute myocardial infarction. Dan Med Bull 1978; $27: 51-5$.

${ }^{25}$ Farquhar JW, Maccoby N, Wood PD, et al. Community education for cardiovascular health. Lancet $1977 ; \mathrm{i}: 1192-5$

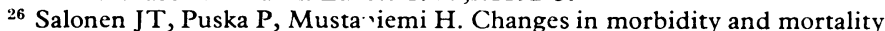
during comprehensive comımunity programme to control cardiovascular diseases during 1972-7 in North Karelia. Br Med F 1979;ii:1178-83.

${ }^{27}$ McNeill GP, Bouchier IAD, Watson H. Mobile coronary care available to the general public. Lancet 1979;i:975.

(Accepted 5 April 1982)

\title{
Selective infection of lower respiratory tract by respiratory viruses in children with recurrent respiratory tract infections
}

\author{
D ISAACS，J R CLARKE，D A J TYRRELL， H B VALMAN
}

\begin{abstract}
Thirty preschool children presenting with recurrent respiratory infections and their unaffected siblings were observed prospectively for a year. The index children experienced more episodes of acute respiratory infection than their siblings. Respiratory viruses were the major cause of respiratory infections. The index children had lower respiratory tract disease, predominantly wheeze, during $34 \%$ of proved respiratory virus infections compared with $11 \%$ of such infections experienced by the control children $(p<0.02)$. Atopic children had an increased tendency to wheeze that did not reach significance, but atopy was not associated with increased susceptibility to respiratory infections.
\end{abstract}

\section{Introduction}

There is a large group of children with recurrent respiratory tract infections who are seen by their general practitioners and by paediatricians and for whom conventional immunological tests show no cause for their increased susceptibility to infections. ${ }^{1}$ It is not known whether such children are experiencing mainly viral or bacterial infections. The association between wheezy bronchitis and respiratory virus infections is, however,

Northwick Park Hospital and Clinical Research Centre, Harrow, Middlesex HA1 3UJ

D ISAACS, MRCP, MRC research fellow (present address: Royal Alexandra Hospital for Children, Camperdown, NSW 2050, Australia)

J R CLARKE, BSC, laboratory technician

D A J TYRRELL, FRCP, deputy director, Clinical Research Centre

H B VALMAN, FRCP, consultant paediatrician well documented. Horn and colleagues isolated respiratory viruses from tissue culture in $146(24 \%)$ of 554 episodes of acute wheezy bronchitis in children aged 0 to 12 years, and half of the viruses isolated were rhinoviruses. ${ }^{2}$ The same workers isolated rhinoviruses in large numbers from the sputum of children with wheezy bronchitis, suggesting lower respiratory tract multiplication of the virus. ${ }^{3}$

Some, but not all, children who wheeze during virus infections are atopic. ${ }^{2}{ }^{4}$ Atopy and increased bronchial lability are thought to be determined independently, since children with a persistent increase in bronchial lability after bronchiolitis are not atopic. ${ }^{5}$ It is not known whether atopy is associated with an increased susceptibility to respiratory infections; Minor et al suggested that asthmatic children are more susceptible to respiratory virus infections than their non-asthmatic siblings, ${ }^{6}$ but the total number of respiratory infections experienced by asthmatic and non-asthmatic children in their study was identical and atopic status was not specified.

We undertook a prospective study of 30 preschool children with recurrent respiratory infections and their unaffected siblings.

\section{Patients and methods}

Thirty children aged 6 months to 6 years presenting consecutively to the paediatric department with recurrent upper or lower respiratory tract infections (or both) were admitted to a prospective study. The index children were reported by their parents to have had at least 10 infections in the previous year and all had an unaffected sibling in the same age range who acted as control. Sibling pairs were observed prospectively for a year from admission to the study. The sibling control group was 1.4 years older on average than the index group ( $p<0.05$ by the Student's paired $t$ test). The mean age of the index group at presentation was $2 \cdot 2$ years. Only one index child and one control sibling were under one year of age at presentation. 